\title{
The spectrum of heart disease in adults in Malawi: A review of the literature with reference to the importance of echocardiography as a diagnostic modality
}

\author{
Theresa J. Allain ${ }^{1}$, Louis Kinley², Bright Tsidya ${ }^{2}$, Ailsa Murray ${ }^{1}$, Mark Cheesman $^{3}$, Sam \\ Kampondeni ${ }^{2}$, Noel Kayange ${ }^{1}$
}

1. Department of Medicine, College of Medicine, University of Malawi, Blantyre, Malawi

2. Department of Radiology, Queen Elizabeth Central Hospital, Blantyre, Malawi

3. North Bristol NHS Trust, Bristol, United Kingdom

Correspondence to: Theresa J. Allain (theresa.allain@googlemail.com)

\section{Introduction}

Malawi, like many developing countries, is in a state of health transition from predominately infectious diseases to predominately noncommunicable diseases (NCDs). ${ }^{1-3}$ This transition has caused many countries to have a "double burden" of disease, with high levels of both communicable and noncommunicable pathologies., ${ }^{4,5}$ The transition has coincided with increasing affluence and life expectancy among Malawians. Between 2003 and 2013, life expectancy in Malawi has increased from 37 to 53 years, ${ }^{6}$ with an adjusted life expectancy of 77 years for Malawians who survive to age $60 .{ }^{7}$ Cardiac diseases related to infection may present at any age, but those related to NCDs predominate in older age groups. The spectrum of heart disease can provide an indicator of the health transition from infectious to noninfectious diseases.

Echocardiography is a noninvasive modality for gaining both structural and functional information about the heart. Echocardiography can be used to identify infectionrelated pathology, such as valvular heart disease following rheumatic fever or tuberculous pericardial effusion, ${ }^{8}$ and noncommunicable pathologies such as hypertensive heart disease or cor pulmonale. The information gained can lead to life-saving changes in management. This review will describe the spectrum of adult cardiac disease in Malawi, including changes over time, especially the impact of the HIV epidemic and the health transition from communicable to noncommunicable diseases. Selected studies from the subSaharan region will be reviewed to illustrate the usefulness of echocardiography in diagnosing heart disease when other investigations are not available.

\section{Clinical studies of heart disease from Malawi}

Studies from Malawi are summarised in Table 1a. The earliest accessible study of heart disease in Malawi describes prospective findings in 114 adults and children, aged 6 years and above, seen at a cardiac clinic in Queen Elizabeth Hospital (QECH), Blantyre, in 1974. ${ }^{9}$ The study was conducted before echocardiography was in widespread use, so diagnoses were based on clinical examination, chest x-ray (CXR), and electrocardiogram (ECG). The commonest diagnosis $(23 \%)$ was rheumatic heart disease, mainly in subjects aged less than 20 years. Hypertensive heart disease was diagnosed in 16\% of patients, and $87 \%$ of these were aged 40 years and above (mean age 55 years). In this pre-HIV-era study, $7 \%$ of the study patients were thought to have tuberculous pericarditis and $8 \%$ were diagnosed with right heart failure secondary to pulmonary disease. More recently, a study in northern Malawi described cardiac diagnoses in 3908 patients of http://dx.doi.org/10.4314/mmj.v28i2.7 all ages (2 to 82 years) attending a cardiac clinic at Mzuzu Central Hospital from 2001 to 2005. ${ }^{10}$ This retrospective register analysis utilised all diagnostic modalities available in the cardiac clinic, including physical examination, CXR, echocardiogram, and ECG and clearly demonstrated the double burden of communicable and noncommunicable disease that Malawi is now facing. Valvular heart disease ( $n=1315 ; 33.6 \%$ ) was the commonest diagnosis in the study, with rheumatic heart disease $(n=1176)$ accounting for the majority of these cases. Hypertensive heart disease ( $\mathrm{n}=$ $945 ; 24.2 \%$ ) was the next most frequent, with presentations including renal failure, stroke, and pulmonary oedema. Cardiomyopathy was present in 726 patients (18.6\%), among whom 720 had dilated cardiomyopathy. Pericardial disease accounted for $13.6 \%(n=553)$ of the diagnoses, of which tuberculous pericarditis accounted for 492 cases. Interestingly, there were only 3 cases of suspected coronary artery disease and, in keeping with the emergent epidemic of NCDs, these all presented in 2005, which was the final year of data collection. ${ }^{10}$

\section{Echocardiographic studies in Malawi}

In 2012, a survey was carried out of 117 consecutive echocardiograms done by radiographer technicians, a consultant radiologist, and physicians at QECH. ${ }^{11}$ Fiftyseven per cent of the echocardiograms were performed on women and $72 \%$ on inpatients. Forty-three $(36.8 \%)$ of the study subjects were HIV-positive, $50(42.7 \%)$ were HIV-negative, and 24 were of unknown HIV status. The age range was 15 to 80 years, with a mean age of 47 years. The most frequent reasons for referral were: to investigate symptoms of congestive cardiac failure, to look for pericardial effusion or evidence of pericardial tuberculosis (TB), to look for evidence of hypertensive heart disease, and to investigate suspected rheumatic heart disease. In these echocardiograms, $44 \%$ had left ventricular hypertrophy consistent with hypertensive heart disease, $18 \%$ had a dilated left ventricle, $14 \%$ had a significant pericardial effusion (most likely due to TB), and 9\% had features of rheumatic valvular heart disease (predominately mitral valve disease). Nine per cent had isolated right heart failure, most likely due to pulmonary hypertension and 3\% had regional wall motion abnormalities consistent with ischaemic heart disease. The final description of cardiac disease from Malawi is an overview of echocardiograms carried out at QECH by one physician. ${ }^{12}$ The key findings of these 822 echocardiograms carried out over six years in adult inpatients were prospectively recorded in a logbook. HIV status was not recorded for these patients, but the HIV prevalence in this population 
was more than $80 \% .{ }^{13}$ These data (Table 1) demonstrate that left ventricular failure and pericardial disease were the dominant pathologies. Pericardial disease was likely due to TB in the majority of patients, with pericardial effusion in the context of Kaposi's sarcoma and uraemia making up the remainder. Over the six years of data collection, the relative proportions of the different diagnoses remained similar; however, there were some changes in referral patterns. For example, after the QECH dialysis unit opened, more cases of severe hypertensive heart disease and uraemic pericarditis were seen.

Comparing all of the Malawian studies from 1974 to 2013, there is some suggestion of a changing pattern of disease, with a shift from valvular (mainly rheumatic) heart disease as the most frequent diagnosis in 1974 and 2001 to 2005, to left ventricular failure and pericardial disease in later studies. The increase in pericardial disease has coincided with the HIV epidemic. Right heart failure has remained fairly constant. Differences between the studies also reflect the different patient groups, with outpatient clinic-based studies and those including children showing a different spectrum of diagnoses from inpatient studies. Comparison of the clinical studies to those using echocardiography alone demonstrates that, where resources are limited, clinical examination combined with echocardiography can identify a similar range of diagnoses (see Figure 1) without the need for ECG or additional radiology.

Figure 1: Typical echocardiographic appearances of common conditions

Figure 1a: Rheumatic aortic valve

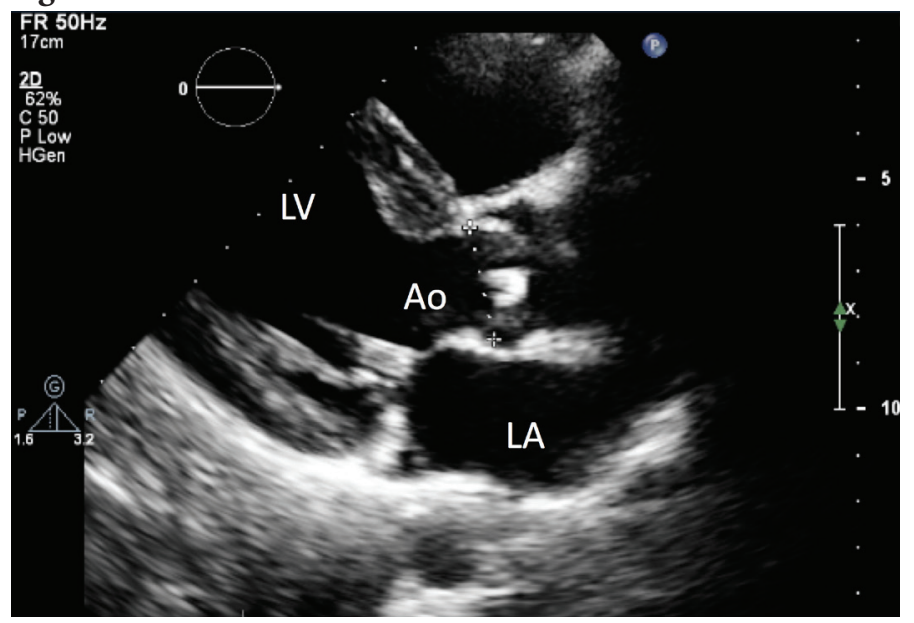

Figure 1b: Rheumatic mitral stenosis (note enlargement of left atrium)

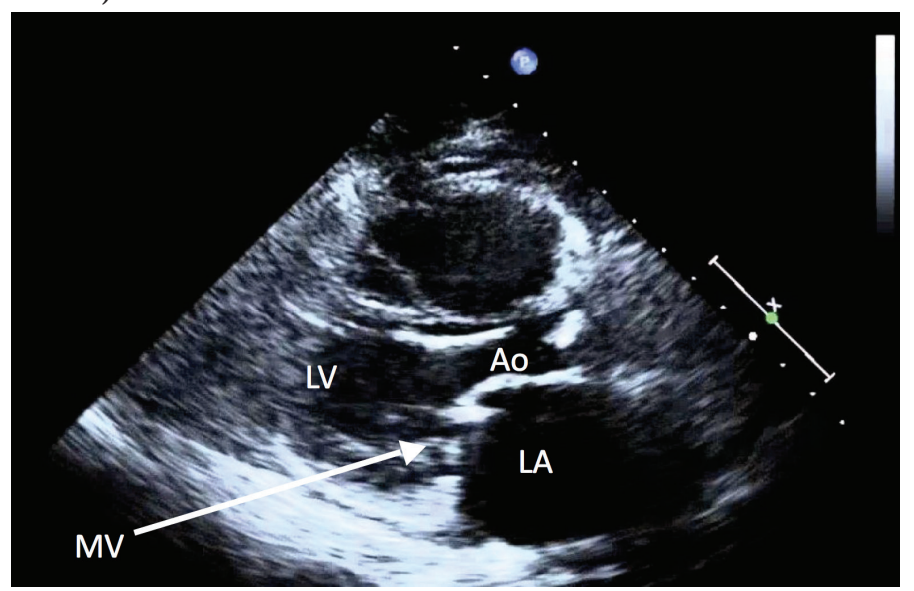

The situation in other sub-Saharan African countries

In 2001, 9\% of all mortality in Africa was due to cardiovascular diseases-mainly hypertension, stroke, cardiomyopathy, and rheumatic valve disease. Of the cardiac deaths, the commonest three cardiac diagnoses were dilated cardiomyopathy, rheumatic heart disease, and hypertensive heart disease. ${ }^{14}$ The profile of cardiac disease throughout Africa is changing and more recent studies, such as the Abuja Heart Study (2006 to 2010) in Nigeria ${ }^{15}$ and the Heart of Soweto Study (2006 to 2008) in South Africa, ${ }^{16,17}$ show that hypertension is now a dominant cause of heart failure in adults in these countries. Considering that approximately onethird of Malawian adults have hypertension - most of which is undiagnosed or poorly controlled ${ }^{1}$ - it is likely that, over the next 10 years, hypertension will become a more prevalent cause of heart disease in Malawi too. The Heart of Soweto study also demonstrated a surprisingly high prevalence of right ventricular failure (RVF); out of all cases diagnosed with heart failure, 14\% had isolated RVF, predominately secondary to chronic obstructive pulmonary disease (COPD), previous TB, or primary pulmonary hypertension. ${ }^{18}$ In Malawi the prevalence of RVF has been consistent over time, at $8 \%$ in Brown and Willis's study of $1974^{\circ}$ and $9 \%$ in the recent echocardiography data from QECH. ${ }^{11}$ Mocumbi and Sliwa have emphasised the importance of heart disease in women, highlighting a prevalence of postpartum cardiomyopathy ranging from 1 per 100 deliveries in some parts of Nigeria to

Figure 1c: Rheumatic mitral valve with vegetation due to endocarditis; small pericardial effusion also evident

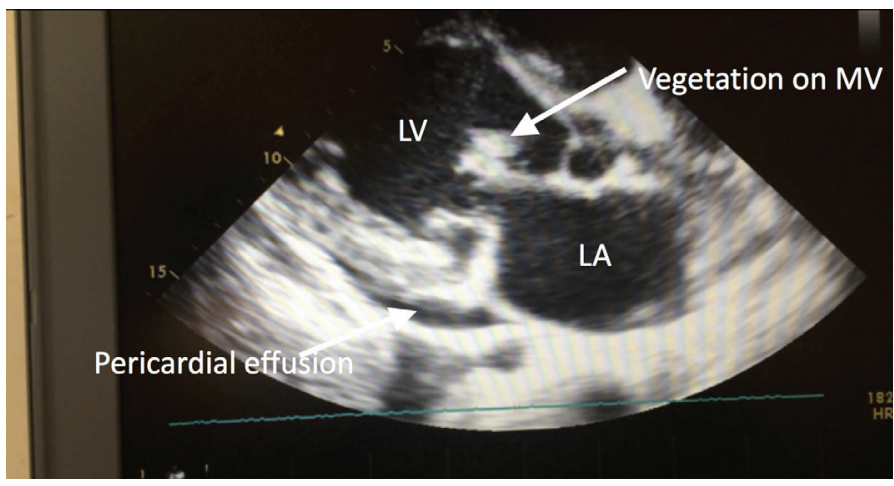

Figure 1d: Pericardial effusion

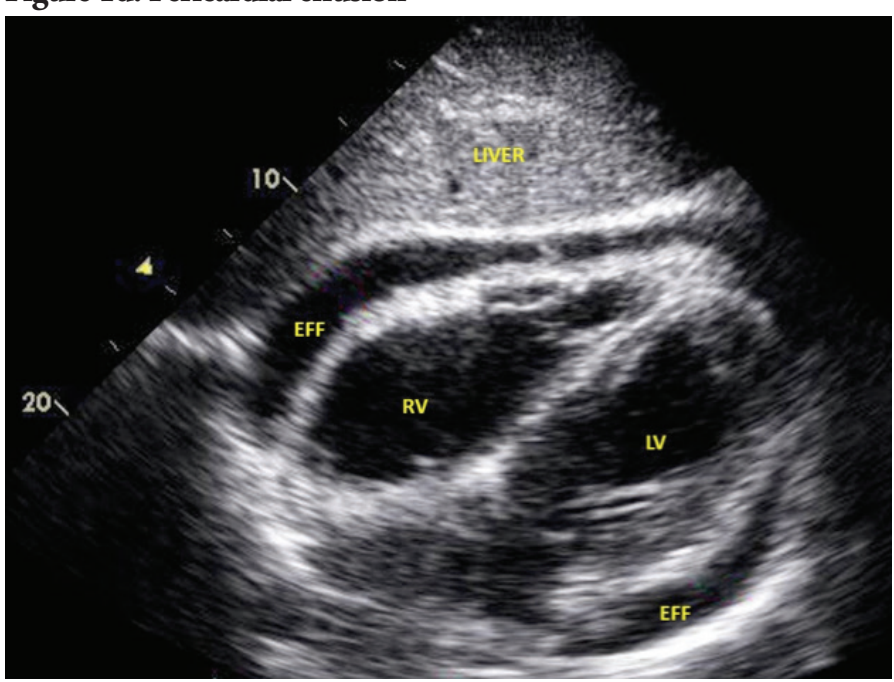

Ao = aortic root; $\mathrm{LA}=$ left atrium; $\mathrm{LV}=$ left ventricle; $\mathrm{RA}=$ right atrium; $\mathrm{RV}=$ right ventricle; $\mathrm{EFF}=$ pericardial effusion 
Table 1: Studies of the spectrum of cardiac conditions from Malawi (1a) and other countries in the sub-Saharan region (1b)

\begin{tabular}{|c|c|c|}
\hline Table 1a & & \\
\hline $\begin{array}{l}\text { Authors } \\
\text { Country [City] } \\
\text { Year(s) }\end{array}$ & $\begin{array}{l}\text { Setting and study design } \\
\mathrm{N} \\
\text { Age group }\end{array}$ & $\begin{array}{l}\text { Patient findings ranked in } \\
\text { order of frequency of finding }\end{array}$ \\
\hline $\begin{array}{l}\text { - Brown and Willis }{ }^{9} \\
\text { - Malawi [Blantyre] } \\
\text { - } 1974\end{array}$ & $\begin{array}{l}\text { - Central Hospital cardiology clinic } \\
\text { * Prospective } \\
\text { * Consecutive referrals } \\
\text { * Clinical diagnoses, no } \\
\quad \text { echocardiography } \\
\text { - N }=114 \\
\cdot \geq 6 \text { years }\end{array}$ & $\begin{array}{l}\text { 1. RhHD } 23 \% \\
\text { 2. Hypertensive HD } 16 \% \\
\text { 3. Cardiorenal failure } 12 \% \\
\text { 4. Non-RhVHD } 10 \% \\
\text { 5. Anaemic heart failure } 10 \% \\
\text { 6. Pulmonary heart disease } 8 \% \\
\text { 7. Pericardial disease } 7 \% \\
\text { 8. CMP 5\% }\end{array}$ \\
\hline $\begin{array}{l}\text { - Soliman and Juma }{ }^{10} \\
\text { - Malawi [Mzuzu] } \\
\text { - 2001-2005 }\end{array}$ & $\begin{array}{l}\text { - Central hospital clinic } \\
\text { * Retrospective } \\
\text { * Cardiology clinic registry } \\
\text { : N = 3908 } \\
\text { - 2-82 years }\end{array}$ & $\begin{array}{l}\text { 1. Valvular HD } 34 \% \\
\text { * (RhHD: } 30 \%) \\
\text { 2. Hypertensive HD } 24 \% \\
\text { 3. CMP: } 19 \% \\
\text { 4. Pericardial disease } 14 \% \\
\text { * (TB pericarditis: } 13 \% \text { ) } \\
\text { 5. Coronary artery disease }<1 \%\end{array}$ \\
\hline $\begin{array}{l}\text { - } \text { Allain }^{12} \\
\text { - Malawi [Blantyre] } \\
\text { - 2007-2013 }\end{array}$ & $\begin{array}{l}\text { - Radiology department } \\
\text { echocardiography list } \\
\text { * Prospective } \\
\cdot \text { N }=822 \text { ( } 24 \% \text { normal scans }) \\
\cdot \geq 14 \text { years }\end{array}$ & $\begin{array}{l}\text { 1. Left ventricular failure } 20 \% \\
\text { 2. Pericardial disease } 19 \% \\
\quad \text { * (of which TB } 89 \% \text { ) } \\
\text { 3. Valvular HD } 12 \% \\
\text { 4. Right heart failure } 9 \% \\
\text { 5. Hypertensive HD } 7.5 \% \\
\text { 6. Ischaemic HD } 1 \%\end{array}$ \\
\hline $\begin{array}{l}\text { - Murray }{ }^{11} \\
\text { - Malawi [Blantyre] } \\
\text { • } 2012\end{array}$ & $\begin{array}{l}\text { - Radiology department } \\
\text { echocardiography list } \\
\text { * Prospective } \\
\text { * } 37 \% \text { HIV-infected } \\
\text { - } \mathrm{N}=117 \\
\text { - } 15-80 \text { years }\end{array}$ & $\begin{array}{l}\text { 1. Hypertensive HD } 44 \% \\
\text { 2. Dilated LV } 18 \% \\
\text { 3. Pericardial disease } 14 \% \\
\text { 4. RhHD } 9 \% \\
\text { 5. Right heart failure 9\% } \\
\text { 6. RWMA consistent with IHD } \\
\quad 3 \%\end{array}$ \\
\hline
\end{tabular}

\begin{tabular}{|c|c|c|}
\hline $\begin{array}{l}\text { Authors } \\
\text { Country [City] } \\
\text { Year(s) }\end{array}$ & $\begin{array}{l}\text { Setting and study design } \\
\mathrm{N} \\
\text { Age group }\end{array}$ & $\begin{array}{l}\text { Patient findings ranked in } \\
\text { order of frequency of finding }\end{array}$ \\
\hline $\begin{array}{l}\text { - Hakim et al. }{ }^{20} \\
\text { - Zimbabwe } \\
\text { - } 1994\end{array}$ & $\begin{array}{l}\text { - Teaching hospital, medical inpatients } \\
\text { * Prospective } \\
\text { * All HIV-infected } \\
\text { - N = } 157 \text { (79 with abnormal scans) } \\
\text { - } 15-65 \text { years }\end{array}$ & $\begin{array}{l}\text { 1. LV dysfunction } 22 \% \\
\text { 2. Pericardial disease } 19 \% \\
\text { 3. Dilated CMP } 9 \% \\
\text { 4. Right ventricular failure } 6 \%\end{array}$ \\
\hline $\begin{array}{l}\text { - Hakim and } \\
\text { Manyemba }{ }^{21} \\
\text { - Zimbabwe } \\
\text { - } 1998\end{array}$ & $\begin{array}{l}\text { - Radiology department } \\
\text { echocardiography list } \\
\text { * Cross-sectional survey } \\
\text { - } \mathrm{N}=1507 \text { (1153 abnormal scans) }\end{array}$ & $\begin{array}{l}\text { 1. RhHD } 25 \% \\
\text { 2. Pericardial disease } 22 \% \\
\text { 3. Dilated CMP } 22 \% \\
\text { 4. Hypertensive HD } 13 \%\end{array}$ \\
\hline $\begin{array}{l}\text { - Stewart et al. } 17 \\
\text { - South Africa (Heart of } \\
\text { Soweto Study) } \\
\text { - } 2006-2008\end{array}$ & $\begin{array}{l}\text { - Cardiac referrals (clinic and } \\
\text { inpatient) } \\
\text { * Prospective } \\
\text { - } \mathrm{N}=5328 \text { ( } 85 \% \text { Black Africans) } \\
\text { - Adults, mean age } 52 \text { years }\end{array}$ & $\begin{array}{l}\text { 1. Hypertensive heart failure } \\
22 \% \\
\text { 2. Hypertensive HD without } \\
\text { failure } 19 \% \\
\text { 3. Valvular HD } 14 \% \\
\text { 4. IHD } 11 \% \\
\text { 5. HIV related } 10 \% \\
\text { 6. CMP } 9 \% \\
\text { 7. Right heart failure } 7 \%\end{array}$ \\
\hline $\begin{array}{l}\text { - Ojji et al. }{ }^{15} \\
\text { - Nigeria } \\
\text { - 2006-2010 }\end{array}$ & $\begin{array}{l}\text { - Cardiac clinic } \\
\text { * Prospective } \\
\text { * All cases of heart failure } \\
\text { - } \mathrm{N}=475 \\
\text { - Adults, mean age } 49 \text { years }\end{array}$ & $\begin{array}{l}\text { 1. Hypertensive HD } 61 \% \\
\text { 2. CMP 24\% } \\
\text { 3. Valvular HD 9\% } \\
\text { * (RhHD 1\%) } \\
\text { 4. Right heart failure } 3 \% \\
\text { 5. Coronary artery disease < } 1 \%\end{array}$ \\
\hline $\begin{array}{l}\text { - Chillo et al.22 } \\
\text { - Tanzania } \\
\text { - 2009-2010 }\end{array}$ & $\begin{array}{l}\text { - Cardiac clinic } \\
\text { * Prospective } \\
\text { * All HIV-infected with cardiac } \\
\quad \text { symptoms } \\
\cdot \mathrm{N}=102 \\
\text { - } 18-72 \text { years }\end{array}$ & $\begin{array}{l}\text { 1. Pericardial effusion } 41 \% \\
\text { 2. Hypertensive HD } 34 \% \\
\text { 3. RhHD } 13 \% \\
\text { 4. Dilated CMP } 10 \%\end{array}$ \\
\hline $\begin{array}{l}\text { - Schwartz et al. }{ }^{23} \\
\text { - Botswana } \\
\text { - } 2012\end{array}$ & $\begin{array}{l}\text { - Echocardiography clinic, all patients } \\
\text { with increased CTR on CXR } \\
\text { * Prospective } \\
* 59 \% \text { HIV infected } \\
\text { - } \mathrm{N}=179 \text { ( } 2 \text { scans were normal }) \\
\text { - } 14-97 \text { years }\end{array}$ & $\begin{array}{l}\text { 1. CMP } 37 \% \\
\text { 2. Pericardial disease } 21 \% \\
\text { 3. Hypertensive HD } 14 \% \\
\text { 4. RhHD } 8 \% \\
\text { 5. Right heart failure } 7 \%\end{array}$ \\
\hline
\end{tabular}

1 per 1000 deliveries in South Africa and high rates of RVF in women, caused by lung disease related to biomass fuel exposure. ${ }^{19}$ Echocardiography was an important modality in defining the cause of heart disease in all of these studies. Some representative studies from the region are presented in Table $1 \mathrm{~b}$.
Rheumatic heart disease continues to be a problem in young adults and children. Rarer conditions, such as endomyocardial fibrosis, which are more prevalent in some countries than others, also deserve consideration. Two large-scale community studies looked at the prevalence of rheumatic heart disease and endomyocardial fibrosis in Mozambique. The studies confirmed both conditions as major public health problems and highlighted the need for local research on neglected diseases. ${ }^{24,25}$ The first survey, in 2007, using clinical and echocardiographic screening, revealed a rheumatic heart disease prevalence of 30.4 per 1000 cases in 2170 randomly selected children aged 6 to 17 years. ${ }^{26}$ In $98.4 \%$ of cases, the mitral valve was affected. It is important to note that in this study only 5 out of 66 cases of rheumatic heart disease were detected clinically; echocardiography was required to make the diagnosis in the other 61 cases. Echocardiography allows for identification of asymptomatic valvular heart disease and early institution of penicillin prophylaxis. The second study assessed a random sample of 1063 subjects of all ages and found a remarkably high endomyocardial fibrosis prevalence of $19.8 \%{ }^{27} \mathrm{~A}$ high prevalence of endomyocardial fibrosis has also been reported in Uganda. ${ }^{28}$

\section{HIV and the heart}

The contribution of HIV to heart disease cannot be ignored in a review of the literature from the region with the highest prevalence of HIV in the world. Cardiac abnormalities are more common in people living with HIV (PLHIV), ${ }^{29-31}$ and this impacts the spectrum of heart disease seen in Malawi. There are a number of mechanisms by which HIV can affect the heart. HIV can directly cause myocarditis and cardiomyopathy but, interestingly, echocardiographic studies have demonstrated that diastolic left ventricular dysfunction is more common than systolic dysfunction. ${ }^{29}$ HIV can cause primary pulmonary hypertension, which may present as RHF. Cardiovascular risk factors, including hypertension, diabetes, and dyslipidaemia are more common in PLHIV, both due to the virus itself and as a result of antiretroviral therapy (ART) increasing susceptibility to coronary artery disease and hypertensive heart disease. Despite this increased susceptibility associated with HIV, coronary heart disease prevalence in PLHIV in South Africa remains low. ${ }^{31}$ A metaanalysis of studies from developed countries found that the relative risk of cardiovascular disease was $1.6(95 \%$ confidence interval, CI, 1.4-1.8) among PLHIV without ART compared with HIV-uninfected people. The relative risk was 2.0 (95\% CI 1.7-2.4) among PLHIV on ART compared with HIVuninfected people and 1.5 (95\% CI 1.4-1.7) compared with treatment-naïve PLHIV. ${ }^{32}$ Finally, a number of opportunistic infections of the heart have been described in PLHIV, the most common of which is pericardial TB. ${ }^{30,31}$ All of these diagnoses can be inferred from echocardiography in the absence of other diagnostic modalities. There is no specific data on HIV and heart disease in Malawi, but a study using echocardiography to screen patients with different durations of exposure to ART is ongoing.

\section{Echocardiography in clinical practice}

In a setting where there are few diagnostic resources it is important to consider which diagnoses can be facilitated by echocardiography. Table 2 illustrates some typical clinical scenarios and how echocardiography can help establish the diagnosis. 
Table 2: Echocardiography in practice - examples of clinical categories, typical clinical questions and possible echocardiographic findings that can support diagnoses in the absence of other investigations

\begin{tabular}{|c|c|c|}
\hline Diagnostic category & Typical clinical questions & Echocardiographic features \\
\hline Ischaemic heart disease & My patient is getting chest pain; could he have IHD? & Regional wall motion abnormalities \\
\hline \multirow[t]{4}{*}{ Heart failure } & My patient has swollen ankles (or body swelling or ascites); does she have heart failure? & LV dysfunction \\
\hline & My patient is breathless; does he have lung disease or is there a cardiac cause? & Valvular heart disease \\
\hline & & RV failure \\
\hline & & Pericardial disease/effusion \\
\hline \multirow[t]{2}{*}{ Hypertension } & My patient is hypertensive; is her blood pressure well controlled? & LVH \\
\hline & & Diastolic LV dysfunction \\
\hline \multirow[t]{2}{*}{ HIV } & My patient is infected with HIV. He is breathless and has swollen ankles; is there a cardiac cause? & LV dysfunction \\
\hline & & Pericardial effusion \\
\hline \multirow[t]{3}{*}{ Stroke } & My patient had a stroke; is there a cardiac cause for this? & Potential sources of embolism (e.g., mitral \\
\hline & & valve disease, atrial fibrillation); \\
\hline & & Evidence of poorly controlled hypertension \\
\hline \multirow[t]{2}{*}{ Pregnancy } & My obstetric patient became acutely short of breath during childbirth; what caused this? & Mitral valve disease \\
\hline & & Postpartum cardiomyopathy \\
\hline \multirow[t]{3}{*}{ Abnormal chest $\mathrm{x}$-ray } & The cardiothoracic ratio is enlarged; what is the cause? & Dilated cardiomyopathy \\
\hline & & LVH \\
\hline & & Pericardial effusion \\
\hline
\end{tabular}

\section{Utility and potential cost benefit of echocardiography}

Ultrasound (US) is increasingly used in resource-limited settings for the diagnosis of medical conditions. The relatively low cost, safety profile, and portability make it an attractive option. ${ }^{33,34}$ In a resource-poor setting, it is one of the main ways that important diagnoses, such as heart failure or pericardial effusion, can be made. ${ }^{33}$ The favourable cost-benefit ratio of echocardiography is strengthened by the multipurpose capabilities and easy availability and maintenance of a US machine; as well as the absence of consumable materials in comparison to other cardiac diagnostic tools, such as catheterization, CXR, and ECG. ${ }^{35}$ A study carried out on the medical wards at QECH showed that US (both abdominal and cardiac) was often utilised early in the diagnostic pathway, with most scans being requested on the basis of clinical findings alone; only $35 \%$ of US requests were made after an $\mathrm{x}$-ray film was already available and $18 \%$ after any sort of blood test results were available. ${ }^{36}$ Of these scans, $69 \%$ were considered "useful" in terms of confirming or refuting a diagnosis and/or leading to a change in management. Many hospitals in Malawi have ultrasound machines that can be used for basic echocardiography. The challenge is to ensure that there are adequately trained technicians and clinicians who can carry out and interpret echocardiograms. The WHO suggest that basic sonography skills can be learned in three to six months. ${ }^{33}$ This requires investment by the Ministry of Health and Christian Health Association of Malawi to achieve improvements in health are and make potential long-term savings.

\section{Conclusions}

The papers cited in this review are a representative (but not exhaustive) selection of the literature. They describe the spectrum of cardiac disease seen in this region and highlight the importance of echocardiography as a clinical and research tool. They also demonstrate the changing patterns of cardiac disease in association with HIV and the health transition associated with increasing affluence and an ageing population. To enable planning for future health services, a greater understanding is needed of the current health profile, including the spectrum of cardiac disease, of adults in Malawi. Echocardiographic studies would make an important contribution to this knowledge.

\section{References}

1. Msyamboza KP, Ngwira B, Dzowela T, Mvula C, Kathyola D, Harries AD, et al. The Burden of Selected Chronic Non-Communicable Diseases and Their Risk Factors in Malawi: Nationwide STEPS Survey. Su Z, editor. PLoS One. 2011 May 23;6(5):e20316.

2. Mathers CD, Loncar D. Projections of Global Mortality and Burden of Disease from 2002 to 2030. Samet J, editor. PLoS Med. 2006 Nov 28;3(11):e442.

3. Caldwell JC. Population health in transition. Bull World Health Organ. 2001;79(2):159-60.

4. Temu F, Leonhardt M, Carter J, Thiam S. Integration of noncommunicable diseases in health care: tackling the double burden of disease in African settings. Pan Afr Med J. African Field Epidemiology Network; 2014;18.

5. Oni $\mathrm{T}$, Unwin $\mathrm{N}$. Why the communicable/non-communicable disease dichotomy is problematic for public health control strategies: implications of multimorbidity for health systems in an era of health transition. Int Health. 2015 Nov;7(6):390-9.

6. Matchaya GC. Trends in life expectancy and the macroeconomy in Malawi. Malawi Med J. 2007 Dec;19(4):154-8.

7. Global AgeWatch Index 2015 [Internet]. www.helpage.org. London: HelpAge International; 2015 [cited 2015 Jul 8]. Available from: http:// www.helpage.org/global-agewatch/

8. Maher D, Harries AD. Tuberculous pericardial effusion: a prospective clinical study in a low-resource setting-Blantyre, Malawi. Int J Tuberc Lung Dis. 1997;1(4):358-64. 
9. Brown KG, Willis WH. Cardiac disease in Malawi. S Afr Med J. 1975 May 31;49(23):926-30.

10. Soliman EZ, Juma H. Cardiac Disease Patterns in Northern Malawi: Epidemiologic Transition Perspective. J Epidemiol. 2008;18(5):204-8.

11. Murray A. [An Insight into structural heart disease in medical patients, Queen Elizabeth Central Hospital. A four-week elective project report submitted in partial fulfilment of the Bachelor of Medicine and Bachelor of Surgery degree at the University of Aberdeen]. Unpublished report. University of Aberdeen, Aberdeen, United Kingdom; 2012.

12. Allain TJ. [Summary of a logbook of echocardiograms carried out on medical patients at Queen Elizabeth Central Hospital by TJA, 2008-2013]. Unpublished raw data. College of Medicine, University of Malawi, Blantyre, Malawi; 2013.

13. SanJoaquin MA, Allain TJ, Molyneux ME, Benjamin L, Everett $\mathrm{DB}$, Gadabu O, et al. Surveillance programme of in-patients and epidemiology (SPINE): implementation of an electronic data collection tool within a large hospital in Malawi. PLoS Med. 2013 Mar 12;10(3):e1001400.

14. Kadiri S, Reddy K, Yusuf S, Cooper R, Rotimi C, Kaufman J, et al. Tackling cardiovascular disease in Africa. BMJ. 2005 Oct 1;331(7519):711-2.

15. Ojji D, Stewart S, Ajayi S, Manmak M, Sliwa K. A predominance of hypertensive heart failure in the Abuja Heart Study cohort of urban Nigerians: a prospective clinical registry of 1515 de novo cases. Eur J Heart Fail. 2013 Aug;15(8):835-42.

16. Sliwa K, Wilkinson D, Hansen C, Ntyintyane L, Tibazarwa K, Becker A, et al. Spectrum of heart disease and risk factors in a black urban population in South Africa (the Heart of Soweto Study): a cohort study. Lancet. 2008;371(9616):915-22.

17. Stewart S, Carrington M, Pretorius S, Methusi P, Sliwa K, Abegunde $\mathrm{D}$, et al. Standing at the crossroads between new and historically prevalent heart disease: effects of migration and socio-economic factors in the Heart of Soweto cohort study. Eur Heart J. 2011 Feb;32(4):492-9.

18. Stewart S, Mocumbi AO, Carrington MJ, Pretorius S, Burton R, Sliwa K. A not-so-rare form of heart failure in urban black Africans: pathways to right heart failure in the Heart of Soweto Study cohort. Eur J Heart Fail. 2011 Oct;13(10):1070-7.

19. Mocumbi AO, Sliwa K. Women's cardiovascular health in Africa. Heart. 2012 Mar;98(6):450-5.

20. Hakim JG, Matenga JA, Siziya S. Myocardial dysfunction in human immunodeficiency virus infection: an echocardiographic study of 157 patients in hospital in Zimbabwe. Heart. 1996 Aug;76(2):161-5.

21. Hakim JG, Manyemba J. Cardiac disease distribution among patients referred for echocardiography in Harare, Zimbabwe. Cent Afr J Med. 1998 Jun;44(6):140-4.

22. Chillo P, Bakari M, Lwakatare J. Echocardiographic diagnoses in HIV-infected patients presenting with cardiac symptoms at Muhimbili National Hospital in Dar es Salaam, Tanzania. Cardiovasc J Afr. 2012 Mar;23(2):90-7.
23. Schwartz T, Magdi G, Steen TW, Sjaastad I. HIV as a risk factor for cardiac disease in Botswana: a cross-sectional study. Int Health. 2012 Mar;4(1):30-7.

24. Mocumbi AO, Ferreira MB. Neglected cardiovascular diseases in Africa: challenges and opportunities. J Am Coll Cardiol. 2010;55(7):680-7.

25. Mocumbi AO. Lack of focus on cardiovascular disease in subSaharan Africa. Cardiovasc Diagn Ther. 2012;2(1):74-7.

26. Marijon E, Ou P, Celermajer DS, Ferreira B, Mocumbi AO, Jani D, et al. Prevalence of Rheumatic Heart Disease Detected by Echocardiographic Screening. N Engl J Med. 2009;357:470-6.

27. Mocumbi AO, Ferreira MB, Sidi D, Yacoub MH. A population study of endomyocardial fibrosis in a rural area of Mozambique. N Engl J Med. 2009;359:43-9.

28. Freers J, Mayanja-Kizza H, Ziegler JL, Rutakingirwa $M$. Echocardiographic diagnosis of heart disease in Uganda. Trop Doct. 1996 Jul;26(3):125-8.

29. Bloomfield GS, Khazanie P, Morris A, Rabadán-Diehl C, Benjamin LA, Murdoch D, et al. HIV and noncommunicable cardiovascular and pulmonary diseases in low- and middle-income countries in the ART era: what we know and best directions for future research. J Acquir Immune Defic Syndr. 2014 Sep;67:S40-53.

30. Magula NP, Mayosi BM. Cardiac involvement in HIV-infected people living in Africa: a review. Cardiovasc J South Africa. 14(5):2317.

31. Sliwa K, Carrington MJ, Becker A, Thienemann F, Ntsekhe $\mathrm{M}$, Stewart S, et al. Contribution of the human immunodeficiency virus/acquired immunodeficiency syndrome epidemic to de novo presentations of heart disease in the Heart of Soweto Study cohort. Eur Heart J. 2012 Apr;33(7):866-74.

32. Islam F, Wu J, Jansson J, Wilson D. Relative risk of cardiovascular disease among people living with HIV: a systematic review and metaanalysis. HIV Med. 2012 Apr;13(8).

33. World Health Organization. Training in diagnostic ultrasound: essentials, principles and standards [Internet]. WHO Technical Report Series. Geneva: World Health Organization; 1998 [cited 2015 Oct 10]. Available from: http://apps.who.int/iris/bitstream/10665/42093/1/ WHO_TRS_875.pdf

34. Mindel S. Role of imager in developing world. Lancet. 1997;350(9075):426-9.

35. Engel ME, Haileamlak A, Zühlke L, Lemmer CE, Nkepu S, van de Wall M, et al. Prevalence of rheumatic heart disease in 4720 asymptomatic scholars from South Africa and Ethiopia. Heart. 2015 Sep;101(17):1389-94.

36. Brindle HE, Allain TJ, Kampondeni S, Kayange N, Faragher B, Bates I, et al. Utilization of ultrasound in medical inpatients in Malawi. Trans R Soc Trop Med Hyg. 2013 Jul;107(7):405-10. 